\title{
Cardiac Autonomic Neuropathy: A Progressive Consequence of Chronic Low-Grade Inflammation in Type 2 Diabetes and Related Metabolic Disorders
}

\author{
Nour-Mounira Z. Bakkar ${ }^{1}{ }^{\circledR}$, Haneen S. Dwaib ${ }^{1}\left(\mathbb{D}\right.$, Souha Fares ${ }^{2}$, Ali H. Eid ${ }^{1,3,4}{ }^{\circledR}$, \\ Yusra Al-Dhaheri ${ }^{5, *}$ and Ahmed F. El-Yazbi ${ }^{1,6, *(1)}$ \\ 1 Department of Pharmacology and Toxicology, Faculty of Medicine, American University of Beirut, \\ Riad El-Solh 1107 2020, Beirut 11-0236, Lebanon; nb87@aub.edu.lb (N.-M.Z.B.); \\ hsd12@mail.aub.edu (H.S.D.); ae81@aub.edu.lb (A.H.E.) \\ 2 Rafic Hariri School of Nursing, American University of Beirut, Riad El-Solh 1107 2020, \\ Beirut 11-0236, Lebanon; sf31@aub.edu.lb \\ 3 Department of Basic Medical Sciences, College of Medicine, QU Health, Qatar University, Doha 2713, Qatar \\ 4 Biomedical and Pharmaceutical Research Unit, QU Health, Qatar University, Doha 2713, Qatar \\ 5 Department of Biology, College of Science, United Arab Emirates University, Al-Ain 15551, UAE \\ 6 Department of Pharmacology and Toxicology, Faculty of Pharmacy, Alexandria University, \\ Alexandria 21521, Egypt \\ * Correspondence: yusra.aldhaheri@uaeu.ac.ae (Y.A.-D.); ae88@aub.edu.lb (A.F.E.-Y.)
}

Received: 7 October 2020; Accepted: 18 November 2020; Published: 27 November 2020 updates

\begin{abstract}
Cardiac autonomic neuropathy (CAN) is one of the earliest complications of type 2 diabetes (T2D), presenting a silent cause of cardiovascular morbidity and mortality. Recent research relates the pathogenesis of cardiovascular disease in T2D to an ensuing chronic, low-grade proinflammatory and pro-oxidative environment, being the hallmark of the metabolic syndrome. Metabolic inflammation emerges as adipose tissue inflammatory changes extending systemically, on the advent of hyperglycemia, to reach central regions of the brain. In light of changes in glucose and insulin homeostasis, dysbiosis or alteration of the gut microbiome (GM) emerges, further contributing to inflammatory processes through increased gut and blood-brain barrier permeability. Interestingly, studies reveal that the determinants of oxidative stress and inflammation progression exist at the crossroad of CAN manifestations, dictating their evolution along the natural course of T2D development. Indeed, sympathetic and parasympathetic deterioration was shown to correlate with markers of adipose, vascular, and systemic inflammation. Additionally, evidence points out that dysbiosis could promote a sympatho-excitatory state through differentially affecting the secretion of hormones and neuromodulators, such as norepinephrine, serotonin, and $\gamma$-aminobutyric acid, and acting along the renin-angiotensin-aldosterone axis. Emerging neuronal inflammation and concomitant autophagic defects in brainstem nuclei were described as possible underlying mechanisms of CAN in experimental models of metabolic syndrome and T2D. Drugs with anti-inflammatory characteristics provide potential avenues for targeting pathways involved in CAN initiation and progression. The aim of this review is to delineate the etiology of CAN in the context of a metabolic disorder characterized by elevated oxidative and inflammatory load.
\end{abstract}

Keywords: cardiac autonomic neuropathy; inflammation; reactive oxygen species; type 2 diabetes

\section{Introduction}

Cardiac autonomic neuropathy (CAN) is one of the earliest manifestations of type 2 diabetes (T2D). It constitutes the major cause of silent cardiovascular events in patients without overt cardiac disease. 
The high prevalence of CAN in patients newly diagnosed with T2D [1] suggests that its pathophysiology is rooted in an earlier stage of metabolic derangement, possibly being prediabetes. Recent knowledge about the nature of disease progression has led researchers to study the status of CAN in patients with recent-onset diabetes. Interestingly, comparisons between type 1 and type 2 diabetic individuals further confirm the fact that CAN processes in T2D start earlier than the onset of overt metabolic impairment [2]. To this end, guidelines recommend CAN screening in T2D patients as early as their first diagnosis as opposed to 5 years after onset in T1D [3]. Thus, it follows that dysglycemia is not the exclusive cause responsible for the initiation of CAN and its progression in T2D. This is clearly reflected when comparing the risk factors of CAN in both diseases. Above poor glycemic control in T1D, obesity and its associated dyslipidemia, hyperinsulinemia, and hypertension (HTN) present additional risk factors for CAN in T2D [4]. Hence, different factors in the etiology of the disease are shown to contribute differentially to CAN manifestations.

Two types of autonomic dysfunction can be associated with diabetes, either intrinsic or extrinsic [5]. The first is related to an insult caused directly to autonomic nerves, whereas the other can be secondary to cardiovascular dysfunction, such as dilated cardiomyopathy and aortic stiffness. Studies concerned with investigating the major contributors to cardiac autonomic dysfunction in T2D have indicated that it is primarily intrinsic in nature [6,7].

Clinically, different tests are used to assess CAN and the function of the different arms of autonomic control. These include, but are not limited to, the Valsalva maneuver (Table 1), deep breathing, and lying to standing - which constitute the Ewing battery tests-and orthostatic hypotension. While the latter was shown to be indicative of the integrity of sympathetic function, the former are reflective of the cardiovagal status. Various parameters can be calculated from CAN assessment tests. These represent the indices of heart rate variability (HRV) (Table 2) and baroreceptor/reflex sensitivity (BRS), and include various time- and frequency-domain parameters [5]. While time-domain parameters reflect the degree of dispersion in a dynamic timeseries (of heart rate (HR) or blood pressure (BP)), frequency-domain parameters separate a particular waveform into its three major components: high, low, and very low frequency (HF, LF, and VLF, respectively) [5]. While HF was shown to be indicative of parasympathetic function and VLF of sympathetic integrity, LF has been tied to both sympathetic and parasympathetic functionality.

Table 1. The Valsalva maneuver: expected responses in healthy individuals [8].

\begin{tabular}{ccc}
\hline Phase & Maneuver & Hemodynamic Change \\
\hline 1 & Onset of forced expiration & BP increases \\
2-shortest R-R interval & Continued forced exhalation & BP increases \\
3 & Release of forced expiration & Reflex tachycardia (R-R decreases), SNS activation \\
& BP decreases \\
$4-$ longest R-R interval & Continued release of forced expiration & BP increases \\
& & Reflex bradycardia (R-R increases), PSNS activation \\
\hline
\end{tabular}

BP: blood pressure, HR: heart rate, PSNS: parasympathetic nervous system, SNS: sympathetic nervous system.

Technically, parameters of BRS quantify the change of HRV with respect to BP variability. BRS reflects the ability of baroreceptors in carotid sinus and aortic arch to detect changes in aortic distention and relay them to brainstem nuclei responsible for cardiac autonomic control [9]. Specifically, the nucleus of tractus solitary is responsible for parasympathetic discharge, while the rostral ventrolateral medulla drives sympathetic outflow [10]. In fact, two checkpoints, mediated by the status of baroreceptors, can determine the strength of the relationship between changes in BP and reflex modulation of HR. The first corresponds to physical properties of the vascular system carrying pressure signals to baroreceptors, while the second represents the major effector in the autonomic nervous system. The latter is referred to as neuronal BRS while the former is referred to as mechanical BRS. Studies in T2D patients have indicated that autonomic neuropathy is a stronger determinant 
of BRS than carotid stiffness [6]. To this end, different studies have turned their attention toward the characterization of changes in the different ganglia and nuclei in the cardiac neural network in metabolic syndrome [11], prediabetes [12], and T2D [13-15].

Table 2. Heart rate variability parameters. BRS, baroreceptor/reflex sensitivity.

\begin{tabular}{|c|c|c|}
\hline Heart Rate Variability (HRV) & Description & Clinical Significance \\
\hline \multirow{11}{*}{$\begin{array}{l}\text { Time-domain analysis [2] } \\
\text { standard deviations (SDs) }\end{array}$} & $\begin{array}{c}\text { SD: } \\
\text { SD of } \mathrm{N}-\mathrm{N} \text { intervals }\end{array}$ & Overall \\
\hline & SDNN: & \\
\hline & SD of difference between successive & Overall autonomic function \\
\hline & $\mathrm{N}-\mathrm{N}$ intervals & \\
\hline & SDANN: & \\
\hline & SD of average of differences & Overall autonomic function \\
\hline & $\begin{array}{c}\text { between successive } \mathrm{N}-\mathrm{N} \text { intervals } \\
\text { percentNN50: }\end{array}$ & \\
\hline & percentage occurrence of $\mathrm{N}-\mathrm{N}$ & Parasympathetic function \\
\hline & intervals above $50 \mathrm{~ms}$ & \\
\hline & RMSSD: & \\
\hline & Root mean square of the differences & Parasympathetic function \\
\hline & between successive $\mathrm{N}-\mathrm{N}$ intervals & Longest: after release of the maneuver \\
\hline Valcalya ratio & longest $\mathrm{R}-\mathrm{R}$ interval & (phase 4: reflex bradycardia, parasympathetic) \\
\hline Valsalva ratio & shortest $R-R$ interval & Shortest: during the maneuver \\
\hline \multirow{5}{*}{ Frequency-domain analysis } & & (phase 2: reflex tachycardia, sympathetic) \\
\hline & Very low frequency (VLF) & Sympathetic \\
\hline & Low frequency (LF) & Parasympathetic and sympathetic, reflective of BRS \\
\hline & High frequency $(\mathrm{HF})$ & Parasympathetic \\
\hline & Low/high frequency ratio (LF/HF) & Sympatho-vagal balance \\
\hline
\end{tabular}

\section{Rationale}

This review focuses mainly on the determinants of CAN on the progression from prediabetes to T2D. It also describes a temporal framework for the different manifestations of such a complication, explaining how multiple disease components can have differential impacts on symptoms. While innumerable studies have investigated the effect of these different factors in various disease conditions, a significant need remains to examine them collectively along the natural history of T2D. Our aim was to review these changes in T2D subjects and animal models with a focus on the role of local and systemic inflammatory changes and their ensuing impact on peripheral and central effectors including neuronal oxidative stress and autophagy.

\section{The Metabolic Syndrome: A Continuum of Low-Grade Pro-Oxidative and Proinflammatory Processes}

Current understanding of the metabolic syndrome reveals the presence of an inflammatory component. Different mechanisms in the course of progression to T2D trigger the initiation of inflammatory processes that are varied in nature but are essentially linked [16]. The so-called "metabolic inflammation" (also known as meta-inflammation) distinguishes T2D from T1D. Interestingly, a population-based study comparing inflammatory profiles in normoglycemic, prediabetic, and T2D individuals offered a spectrum of differential change in inflammatory biomarkers with disease progression [17].

\subsection{The Role of Altered Glucose Homeostasis in Meta-Inflammation}

In the prediabetic stage, changes in glucose and insulin homeostasis have been shown to be linked to inflammation pathogenesis even before the advent of hyperglycemia [18,19]. An increase in insulin demand and production secondary to insulin resistance is accompanied by elevated pancreatic endoplasmic reticulum stress initiating pro-oxidative and proinflammatory processes [20,21]. Additionally, hyperinsulinemia-induced lipid storage was shown to promote adipose tissue-specific inflammation and a subsequent acute phase response [22,23]. This was shown to be mediated by 
adipose tissue expansion promoting hypoxia of poorly vascularized tissues, which constitutes the driving force for the activation of nuclear factor- $\mathrm{kB}(\mathrm{NF}-\mathrm{kB})$, a sensor of oxidative stress [24]. On the activation of NF- $\mathrm{kB}$, adipose tissues secrete proinflammatory cytokines such as interleukin-6 (IL-6) and tumor necrosis factor $\alpha$ (TNF- $\alpha$ ), which promote liver synthesis of acute phase proteins such as $C$ reactive protein (CRP) and plasminogen activator inhibitor-1 (PAI-1) $[25,26]$. Consequently, adipose tissue hypertrophy leads to apoptosis attracting macrophages in crown-like structures $[27,28]$. Immune cells release reactive oxygen species (ROS) in response to cytokine upregulation [29]. Moreover, overnutrition overwhelms inherent mitochondrial capacity for scavenging excess ROS produced by metabolic processes promoting further upregulation of proinflammatory processes through NF- $\mathrm{kB}$ pathways [30]. On the onset of hyperglycemia, however, elevated mitochondrial aerobic respiration and activity of the electron transport chain, as well as advanced glycated end products, aggravates oxidative stress, which presents another activator of inflammatory cascades mediated by NF- $\kappa B$, cAMP-regulated element-binding protein, and activator protein 1 [31]. Additionally, neurohormonal stimulation by the renin-angiotensin-aldosterone system (RAAS) was shown to play a role in aggravating oxidative stress and inflammation [32].

Interestingly, metabolic inflammatory processes are evident in the cardiovascular, neuronal, and neurovascular systems, indicating their possible involvement in the etiology of cardiac autonomic dysfunction in the metabolic syndrome [33-35]. Hypoxia driven by vascular dysfunction activates immune cells of the central nervous system, producing cytokines such as IL-1 $\beta$, which in turn triggers effectors downstream of NF- $\mathrm{kB}$ further producing cytokines such as IL-6. Additionally, the metabolic syndrome is a known disrupter of the integrity of the blood-brain barrier (BBB) via altering the permeability of the choroid plexus [36,37]. This was attributed to increased ROS production leading to decreased expression of tight junction proteins. Hence, it promotes infiltration of proinflammatory cytokines and immune cells from the bloodstream to the central nervous system, especially in the context of systemic inflammation characteristic of T2D. The latter contributes to compromising BBB functions by increasing the permeability of the basement membrane of the BBB, via matrix metalloproteases [38], allowing for immune cell extravasation and upregulating leukocyte adhesion molecules, such as intracellular adhesion molecule-1 (ICAM-1), vascular cell adhesion molecule-1 (VCAM-1), P-selectin, and E-selectin [37]. In fact, increased oxidative stress in the diabetic brain is related to decreased antioxidant defense enzymes and molecules concomitant with an increase in the polyol pathway resulting in a decrease in NADPH recycling [39]. It was also shown that hyperinsulinemia can lead to increased neuronal oxidative stress through decreased mitochondrial PI3K/Akt signaling pathway [40]. Such changes were shown to be associated with autophagic disturbances in different peripheral and central neurons [39,41,42]. Alternatively, accumulation of ROS-generating mitochondria resulting from autophagy suppression could activate, in addition to NF- $\mathrm{KB}$, the NLRP3 inflammasome responsible for proinflammatory cytokine maturation [39]. Additionally, mitochondrial oxidative damage was shown to be accompanied by a decrease in ATP levels resulting from suppressed mitochondrial energization potential. Hence, the aforementioned changes could ultimately lead to neuroinflammation.

\subsection{Contribution of Gut Microbiota to Meta-Inflammation}

Alterations in the gut microbiome (GM) or dysbiosis has been recently linked to many morbidities, such as metabolic and immune-related disorders [43]. The GM community can affect the host health via two routes: the bacterial components or pathogen-associated molecular patterns (PAMPs), including cell-wall constituents such as lipopolysaccharides (LPS) [44], and the metabolites produced when digesting and processing food in the gut. Hence, dysbiosis outcomes depend on the bacterial Phyla alterations in the gut [45]. Moreover, GM plays a vital role in regulating the permeability of intestinal mucosa [46]. GM manipulates the host's metabolism; hence, dysbiosis was found to be linked to some compromised metabolic states and related diseases [47].

One of the major contributors to dysbiosis is dietary intake. A high-fat diet (HFD), implicated in the production of the metabolic challenge leading to metabolic syndrome and $\mathrm{T} 2 \mathrm{D}$, promotes an 
increase in serum LPS. This was proposed to occur due to increased permeability of the gut by the microbiota, which is linked to metabolic endotoxemia. LPS acts through the Toll-like receptor 4 (TLR4) signaling pathway, where TLR4 is expressed on macrophages and adipose tissue and is activated upon LPS recognition. The LPS/TLR4 complex has two main signaling pathways: the MyD88-independent pathway that gives rise to Type 1 interferons (IFNs) and the MyD88-dependent pathway that activates proinflammatory cytokines such as IL-1, IL-6 and TNF- $\alpha$. Both pathways act via NF-kB [48-50]. Thus, upon activation, this complex stimulates white adipose tissue inflammation and proinflammatory macrophage infiltration and is also linked to an increase in monocyte chemoattractant protein-1 (MCP-1) [51].

In addition to that, work on mice tissues showed that an HFD enhanced the transport of LPS through chylomicrons, rather than the traditional paracellular pathway [52,53]. Increased gut permeability, endotoxemia, and fatty liver were also observed in animal models fed a high-fructose diet, HFD, or both [44]. Upon the discovery of the importance of the gut microbiota in dictating metabolic status, different nutritional supplementations were introduced in an attempt to manage the colonic composition of bacteria. These are pre-, pro-, and postbiotics [54]. Whereas probiotics are essentially exogenous microbial supplements aimed at optimizing microbial balance, their effects are rather transient. Prebiotics, on the other hand, are nondigestible food ingredients, such as fructo-oligosaccharides, which promote the growth/activity of select endogenous bacteria residing in the gut [55]. Alternatively, postbiotics are the metabolites produced by probiotics, specifically lactic acid bacteria [54]. Interestingly, animals treated with pre-, pro- and postbiotics showed an improved integrity of the intestinal barrier [56-58] and, consequently, a reduction in endotoxemia, fatty liver, glucose intolerance, and obesity [59]. Hereafter, dysbiosis often leads to increased gut permeability through reduced expression of tight junction proteins and mucins [60] or the consumption of gut mucus by the GM in the absence of dietary fiber intake [59].

Moreover, the type of fat in the diet determines the changes in GM community. For example, some research showed that unsaturated fatty acids such as fish oil increased Lactobacillus abundance in the gut, which is known to be correlated with lean phenotype and reduced adipose tissue inflammation and macrophage infiltration. Akkermansia muciniphila and Bifidobacterium showed similar positive effects to Lactobacillus. On the other hand, a saturated-fat diet is highly linked to an increase in some taxa such as Bilophila, Bacteroides, and Turicibacter, which in turn appear to increase adiposity, adipose tissue inflammation, insulin insensitivity, and TLR4 activation. Furthermore, these taxa were found to activate the MyD88-dependent pathway among lard-fed animals and were correlated with increased inflammation of white adipose tissue and size of adipocytes $[45,49,61]$. This was confirmed in MyD88-deficient mice fed a lard-rich diet, as these mice had smaller adipocytes and did not develop obesity, compared to their wildtype lard-fed littermates [49]. Moreover, a deletion of MyD88 was associated with reduced macrophage inflammatory response and aortic lesions [45].

A Gram-negative microbiota was proposed to exacerbate the high-fat effect in murine models via the TLR4 pathway. Interestingly, TLR4 knockout (KO) models fed an HFD had intact gut integrity compared to wildtype HFD-fed mice [62]. Moreover, TLR4 KO mice showed a resistant phenotype to cardiovascular diseases [63]. According to some evidence, dysbiosis is correlated to paracellular permeability, which is associated with compromised expression and localization of tight junction proteins in the epithelial layer, especially occludin and zonula occludens- 1 in the small intestine [43].

Two worthily mentioned metabolites that have major contribution to cardiovascular insults are short-chain fatty acids (SCFAs) and trimethylamine oxide (TMAO). In general, these two metabolites have opposing effects in terms of metabolic and cardiovascular state $[63,64]$. SCFAs, mainly butyrate, acetate, and propionate, are produced by plant polysaccharide-fermenting bacteria, such as Lactobacillus and Bifidobacterium [63,64], which are compromised with the increase in Firmicutes-to-Bacteriodetes ratio [65]. The decrease in SCFAs and their producing bacteria was found to be correlated to HTN and other cardiovascular insults $[63,65,66]$. Furthermore, SCFAs seem to be associated with enhanced gut barrier function, by increasing the expression of mucin and tight junctions proteins $[60,67]$. 
An increase in TMAO is persistently associated with an increased risk of wide array of cardiovascular diseases in T2D and nondiabetic subjects [68], such as atherosclerosis and ischemic heart failure [63]. TMAO is synthesized in the liver from trimethylamine (TMA), a product of choline digestion by gut bacteria, via flavin-containing monooxygenase 3 (FMO3) [64,69,70]. Of note, elevated levels of TMAO are associated with T2D by affecting insulin sensitivity and disrupting its signaling pathway through HFD-induced adipose tissue inflammation [69]. Furthermore, TMAO is linked to endothelial dysfunction by increasing inflammation and adhesion factors [66] and altering endothelial nitric oxide synthase (eNOS) function and nitric oxide (NO) production [64,65]. Moreover, TMAO was found to be involved in activating inflammasome complex in vascular cells and stimulating ROS production [71], in addition to its proatherogenic role $[45,71]$.

Interestingly, GM has been implicated in the control of adipose tissue expansion and inflammation [72] and can consequently be a determinant of systemic inflammation in metabolic diseases such as T2D. Along the same lines, dysbiosis could disrupt the BBB by downregulating endothelial tight junctions, thus promoting neuroinflammation [37].

\section{Progression of CAN: From Metabolic Syndrome and Prediabetes to T2D}

\subsection{Determinants of CAN in Early-Onset and Advanced T2D}

Comparisons with status and manifestations of CAN in T1D implicate different disease-specific characteristics in the initiation and progression of CAN in T2D. Studies conducted by Ziegler et al. assessed the status of CAN in patients with recent onset diabetes, i.e., less than or equal to 1 year after their first diagnosis $[2,73]$. Their results provide indication that the pathophysiologic trigger of CAN in recent-onset T2D is independent of hyperglycemia but rather tied to metabolic characteristics related to obesity (body mass index (BMI) $>30$, central obesity, and increased fat mass) and dyslipidemia, distinguishing this population from their control, and subsequently T1D, counterparts [2]. Indeed, T2D but not T1D patients presented with early parasympathetic and sympathetic blunting compared to controls, independently correlated with insulin resistance (M-value of whole-body insulin sensitivity and T2D; see Table 3). It is worth mentioning, however, that, although this population of T2D patients had elevated systolic BP and HR compared to control (healthy, age-matched subjects), they did not show signs of sympathetic augmentation on HRV assessment, i.e., LF and LF/HF of HRV were not different from controls [2]. Interestingly, these patients showed only a slight increase in $\mathrm{HbA1c}$, potentially ruling out a contribution of glycated end products in the observed phenotype. In particular, unlike T1D patients, recent-onset T2D patients showed hyperinsulinemia, and increased high-sensitivity CRP [2], indicating a possible mechanism for hyperinsulinemia-induced systemic inflammation in the pathogenesis of premature baroreceptor dysfunction. Yet, no correlations among hyperinsulinemia, systemic inflammation, and early baroreceptor blunting, especially sympathetic, were studied in this T2D patient population.

Table 3. Measures of insulin secretion and sensitivity.

\begin{tabular}{ccc}
\hline Parameter & Test & Methodology \\
\hline $\begin{array}{c}\text { Insulin secretion [2] } \\
\text { (hypo- vs. hyperinsulinemia) }\end{array}$ & $\begin{array}{c}\Delta \text { C peptide } \\
\text { Fasting C-peptide } \\
\text { Insulin sensitivity: } \\
\text { Stimulated C-peptide } \\
\text { Incremental area under } \\
\text { the curve (iAUC) } \\
\text { hyperinsulinemic-euglycemic clamp [2] } \\
\text { Whole-body insulin sensitivity }\end{array}$ & $\begin{array}{c}\text { Before and 6 min after glucagon } \\
\text { intravenous (IV) injection }\end{array}$ \\
Whole-body insulin resistance & $\begin{array}{c}\text { Homeostatic model assessment for } \\
\text { insulin resistance (HOMA-IR) [11,74] }\end{array}$ & At basal state \\
Oral glucose tolerance test [18] & OGTT & 2 h after oral administration \\
of 75 g of glucose
\end{tabular}


Interestingly, different studies have brought into the picture another factor in the pathogenesis of CAN in early-onset T2D; this is oxidative stress related to acute glycemic excursions, rather than chronic hyperglycemia. On progress to T2D, changes in glucose tolerance and insulin sensitivity take the form of glycemic variability. Importantly, glycemic variability was shown to have the power of predicting CAN in recent onset, where average glucose level failed [75]. Specifically, glycemic variability was higher in T2D patients with CAN, according to Ewing battery tests, than in those without CAN. A role for systemic oxidative stress in the initiation of early parasympathetic dysfunction was, thus, proposed. This particularly pertains to endothelial dysfunction $[76,77]$ and eventually baroreceptor impairment. In fact, increased ROS production in early metabolic insults was shown to be related to decreased endothelial-dependent hyperpolarization secondary to reduced expression of potassium inward rectifier channels [78]. Such an increase is presumed to bring about elevated vascular tone through impairing eNOS activity, ultimately diminishing NO-induced vasorelaxation [79]. Moreover, a study assessing the relationship between endothelial dysfunction and CAN revealed a positive association between NO and eNOS and measures of cardiovagal control, presenting determinants of endothelial function as biomarkers for the pathogenesis of parasympathetic neuropathy in T2D patients [77].

Interestingly, a study assessed the effect of glycemic variability on BRS in T2D patients and again revealed that its elevation is independently correlated with decreased BRS [80]. Above the detrimental effects of oxidative stress on endothelial function and neuropathy, the study presumed that hyperinsulinemia caused by acute fluctuations in blood glucose could be responsible for the observed blunted BRS [80]. Additionally, results showed that BRS decreased with diabetes duration, indicating worsening status with progression of disease components. However, the study did not distinguish between the different arms of the baroreflex control and, thus, could not specify whether sympathetic or parasympathetic deterioration was responsible for this drop in sensitivity. Indeed, a study assessing the effect of glycemic control and disease duration on HRV in T2D patients revealed that worse glycemic indices and longer duration were accompanied by lower parameters of both sympathetic and parasympathetic determinants of HRV [81]. The impact of glycemic control on CAN could be partially explained by a reduction in antioxidant effectors and increase in prooxidative pathways, leading to neuronal ischemia and subsequent damage [82]. However, the contribution of hyperglycemia to inflammatory biomarkers in T2D cannot be overlooked [83]. Thus, it could be through an exaggerated inflammatory state that hyperglycemia worsens the status of CAN with disease progression [84].

\subsection{Effect of Glucose Homeostasis along the Continuum of Prediabetes to Early-Onset T2D on CAN}

In the same way, comparisons between prediabetic and type 2 diabetic manifestations of CAN allow us to draw conclusions about the pathophysiology of CAN development over the natural course of the disease. Hyperinsulinemia secondary to peripheral insulin resistance is the hallmark of the prediabetic stage [85]. However, the superimposition of hyperinsulinemia with sympathetic augmentation makes it unclear which causes the other. A study of a fructose-induced glucose intolerance in mice revealed that sympathetic augmentation (elevated LF of BP variability) and autonomic imbalance (increase in LF/HF) appear before hyperinsulinemia and other metabolic derangements in the course of the metabolic syndrome [86]. Major research has been channeled to the study of early sympathetic augmentation, vagal withdrawal, and altered sympatho-vagal balance; however, little remains known about the origin and etiology of sympathetic dysfunction at a later stage of the disease. While chronic hyperglycemia appears to be the eliciting factor, orthostatic hypotension was thought to be brought about by damage of efferent vasomotor neurons in splanchnic blood vessels [87]. Moreover, earlier studies reported on cardiac sympathetic denervation $[88,89]$. Little remains discovered, however, about the status of central control of sympathetic activity or central sympathetic neuropathy.

Prior studies demonstrating the presence of early processes culminating in CAN in the metabolic syndrome examined the correlation of different stages of impaired glucose homeostasis, defined by isolated impaired fasting glucose (iIFG) and impaired oral glucose tolerance (IGT), as opposed 
to subjects with normal glucose tolerance (NGT) and newly diagnosed diabetics (NDD) (Table 4), with cardiac autonomic control [8]. In one study, CAN was assessed using two BRS parameters. The first was the Valsalva ratio, corresponding to the longest $\mathrm{R}-\mathrm{R}$ interval resulting from parasympathetic activation over the shortest $\mathrm{R}-\mathrm{R}$ interval resulting from sympathetic activation, while the second was $\alpha_{\mathrm{LF}}$, an index of BRS in the LF region corresponding to sympathetic activity [90]. Results showed that, in the absence of obesity, there is an early decrease in $\alpha_{\mathrm{LF}}$ of BRS in patients with IGT only, which is further complicated by a blunting of the Valsalva ratio in borderline overweight NDD, confirming a deterioration of sympathetic function. Different speculations about the origin of the difference in BRS with nondiabetics were made, including differences in the site (i.e., hepatic vs. muscular) and severity of insulin resistance. However, the levels of blood insulin and inflammatory markers in these different conditions were not given. Importantly, a study by Festa et al. reported a consistent independent correlation between insulin resistance, as revealed by frequently sampled glucose tolerance test, and inflammation among patients with insulin resistance syndrome (IRS), NGT, and IGT [18]. Fasting insulin and proinsulin were also associated with chronic subclinical inflammation in these three categories [18], and elevated CRP levels in T2D patients were shown to be correlated with reduced cardiovagal function [77]. It can, thus, be presumed that insulin-resistance-associated hyperinsulinemia could be at the origin of inflammation producing CAN in patients with IGT.

Table 4. Glycemic status $[8,91]$.

\begin{tabular}{cc}
\hline Normal glucose tolerance (NGT) & FPG $<5.6 \mathrm{mmol} / \mathrm{L}(100 \mathrm{mg} / \mathrm{dL})$ \\
& $2 \mathrm{~h} \mathrm{PG}<7.8 \mathrm{mmol} / \mathrm{L}(<140 \mathrm{mg} / \mathrm{dL})$ \\
\hline Isolated impaired fasting glucose (iIFG) & FPG: $5.6-6.9 \mathrm{mmol} / \mathrm{L}(100-125 \mathrm{mg} / \mathrm{dL})$ \\
& $2 \mathrm{~h} \mathrm{PG}<7.8 \mathrm{mmol} / \mathrm{L}(<140 \mathrm{mg} / \mathrm{dL})$ \\
\hline Impaired glucose tolerance (IGT) & FPG $<7.0 \mathrm{mmol} / \mathrm{L}(126 \mathrm{mg} / \mathrm{dL})$ \\
& $2 \mathrm{~h} \mathrm{PG:} \mathrm{7.8-11.1} \mathrm{mmol/L}(140-199 \mathrm{mg} / \mathrm{dL})$ \\
\hline \multirow{2}{*}{ Newly diagnosed diabetes (NDD) } & FPG $\geq 7.0 \mathrm{mmol} / \mathrm{L}(126 \mathrm{mg} / \mathrm{dL})$ \\
& $2 \mathrm{~h} \mathrm{PG} \geq 11.1 \mathrm{mmol} / \mathrm{L}(\geq 200 \mathrm{mg} / \mathrm{dL})$ \\
\hline
\end{tabular}

\subsection{Influence of Obesity Indices and Dyslipidemia}

When studying CAN in prediabetic and T2D patients, it is important to acknowledge the status of obesity in assessed individuals. Indeed, studies investigating the relationship between obesity and CAN revealed that various factors differentially contribute to the pathogenesis of CAN. In nondiabetic obese men, percentage body fat, waist circumference, and visceral adipose tissue volume were associated with measures of reduced HRV, with percentage body fat correlating with the greatest number of HRV parameters [92]. In fact, obesity was shown to predict development of systemic inflammation [93]. Interestingly, hyperleptinemia was shown to mediate the relationship between visceral fat accumulation and CAN in T2D patients [94]. Additionally, dyslipidemia in the presence of obesity aggravates the blunted baroreflex control in T2D and makes it more resistant to lipid-lowering treatment otherwise effective in nonobese T2D patients [95]. It is noteworthy that dyslipidemia could have detrimental effects on CAN by exacerbating systemic inflammation [83].

\section{Association between Adipose, Vascular, Systemic, and Neuroinflammation and CAN}

As an earlier study implicated hyperinsulinemia rather than insulin resistance in the pathogenesis of CAN, particularly impaired BRS [74], and hyperinsulinemia was shown to be the instigating cause of adipose inflammation independent of obesity [22], it can be speculated that it is through adipose inflammation that hyperinsulinemia affects cardiac autonomic control in the metabolic syndrome. Yet, autonomic, particularly sympathetic, function tends to deteriorate as diabetes progresses. Indeed, a study by Lieb et al. (2012) revealed a particularly decreased total spectral power (TSP), indicative of overall control of HRV in patients with established T2D, which was not otherwise present in newly diagnosed diabetics, who showed isolated parasympathetic blunting [96]. 
In fact, the strongest positive correlation was found to be present between total adiponectin-to-leptin ratio and TSP, indicating a contribution for these counteractive adipokines in dictating sympathetic tone. Additionally, increased PAI-1 was shown to be essentially increased in patients with established T2D compared to those with newly diagnosed diabetes (within 6 months of diagnosis). As such, one can conclude that, while prolonged exposure to hyperglycemia might underlie the observed CAN deterioration in T2D, this seems to occur through exacerbation of adipose tissue inflammation occurring in earlier stages of the disease. Later, Herder et al. (2017) retested the association between inflammation and CAN, especially in patients with new-onset T2D [97]. In this study, they found that the association between IL- 6 and cardiac autonomic reflex tests was rather explained by confounding factors. This is in line with the results of a longitudinal study indicating that the association between baseline IL-6 levels and follow-up HRV measures was dependent on BMI [98], again potentially implicating adipose tissue expansion and inflammation. However, independent inverse associations were found between soluble adhesion molecules such as soluble ICAM and E-selectin and sympathetic and parasympathetic function, respectively, indicating a role for vascular inflammation in CAN [97]. Significantly, our previous studies examined the evolution of inflammatory changes in association with worsening of CAN as the metabolic insult progressed. We show that early prediabetic parasympathetic dysfunction is associated with perivascular adipose tissue inflammation [99]. After the development of hyperglycemia, localized adipose tissue inflammation degenerated into systemic inflammation as evident by increased serum IL-1 $\beta$ and signs of disseminated cardiovascular damage that were associated with increased neuronal oxidative stress, inflammation, and suppressed autophagy in the brainstem with concomitant deterioration of CAN, including both sympathetic and parasympathetic functions [84]. The scheme below, thus, provides evidence of a continuum of events, starting with perivascular adipose inflammation as a priming mechanism for vascular inflammation leading to systemic inflammation, presenting a temporal framework for the pathogenesis and progression of CAN in T2D $[84,99,100]$ (Figure 1).

The observed role for neuroinflammation was emphasized in the previous study by Herder et al. (2017) [97]. Two interesting findings were derived from this study. The first is that, in recent-onset T2D, there was a negative correlation among markers of neuroinflammation, IL-18, and vagal efferent function, indicating that neuroinflammation could be the basis of worsening parasympathetic function at this stage of the disease. However, it is worth noting that, although elevated soluble ICAM was shown to be linked to depressed sympathetic function, increased IL-18 was indicated in increased sympatho-vagal balance. This shows that, although sympathetic function might be blunted, it can continue to be predominant over parasympathetic activity. Accordingly, comparisons made between patients with T1D and T2D showed decreased sympathetic activity in T2D, as indicated by the lower LF power of HR. The other important finding is that, while significant associations were shown to exist between cardiac autonomic function and markers of inflammation, such correlations were inexistent in T1D. This was consistent with results in experimental animals where autonomic dysfunction and neuroinflammation were attenuated when T1D was induced by streptozotocin, as opposed to decompensated T2D developing on a background of adipose tissue inflammation [84].

Examination of neuronal function in light of such an inflammatory milieu revealed several pathways implicated in the pathogenesis of CAN in the progress from metabolic syndrome to T2D. With a compromised BBB function, neuroinflammation becomes evident as systemic inflammatory cytokines are transported across the BBB [101,102]. Interestingly, a study showed that delivery of IL-6 to the nucleus of tractus solitary of rats was associated with blunted reflex bradycardia to increased BP [103]. In our work, a change in the status of autophagy, where systemically induced neuroinflammation presented with markers of suppressed autophagy in the brainstem of type-2 diabetic rats, was associated with worsening parasympathetic BRS and emerging blunted sympathetic BRS [84]. Indeed, cell culture studies confirmed the assumption that a serum factor, rather than hyperglycemia, is involved in neuronal damage culminating in CAN in T2D [84,104,105]. Significantly, incubation of the 
differentiated neuroblastoma cell line with serum from T2D patients with neuropathy was capable of inducing apoptosis in a $\mathrm{Ca}^{2+}$-dependent $\mathrm{K}^{+}$-flux manner [104]. Further study indicated mitochondrial dysfunction and autophagy as a mechanism for serum-mediated neuropathy in T2D [105]. Our work suggests that systemic proinflammatory cytokines are responsible for emerging blunted tachycardic responses in T2D [84]. Indeed, treatment of sympathetic-like neurons with sera from T2D rats recapitulated changes seen in brainstem of these rats. Differentiated pheochromocytoma (PC12) cells presented with increased inflammation concomitant with autophagy suppression. These manifestations were not otherwise seen when treating PC12 cells with sera from prediabetic rats (fed a mild hypercaloric diet) or when challenging them with media containing high macronutrient content (high glucose, high free fatty acids and insulin, or high glucose and free fatty acids).

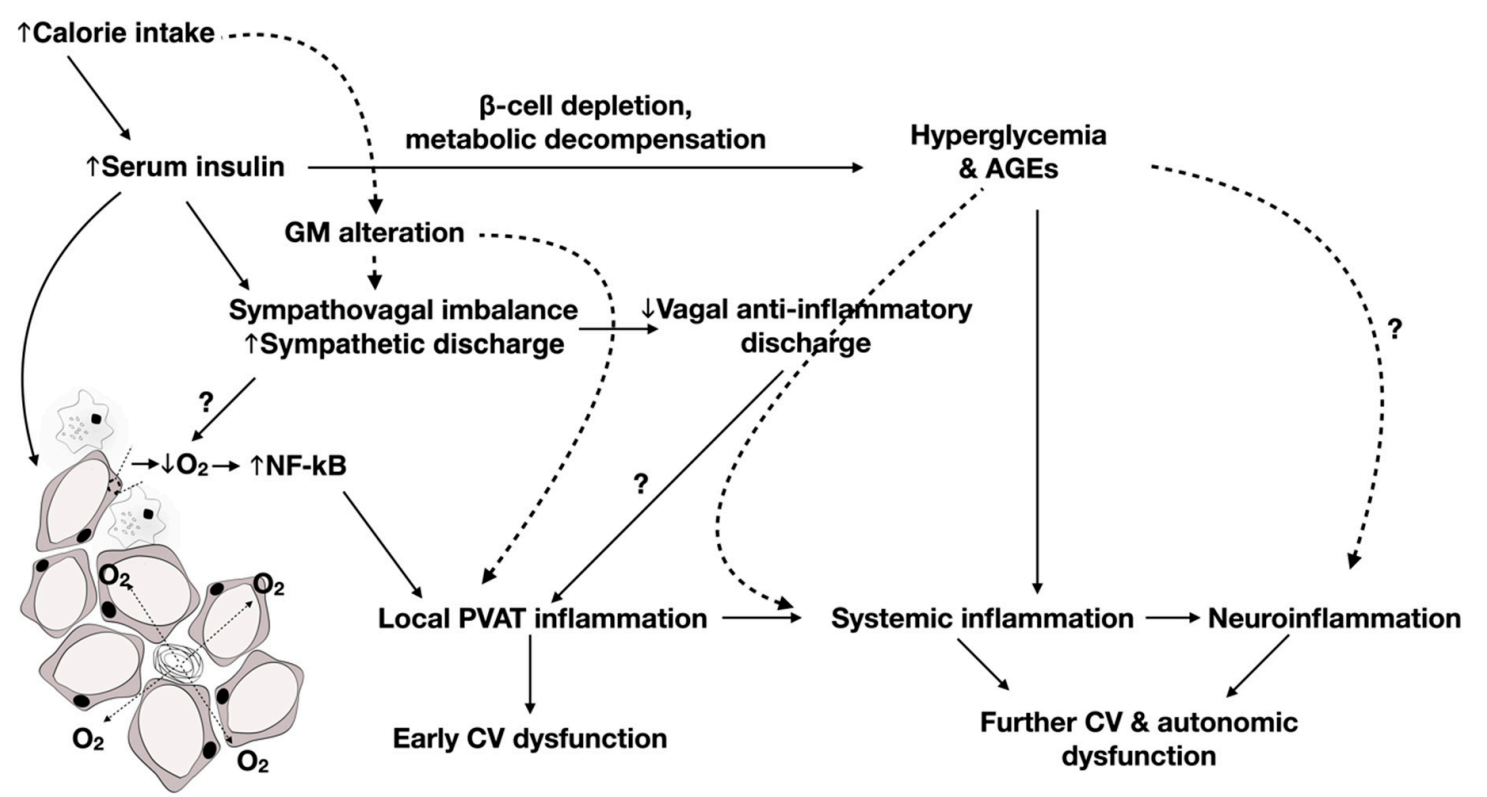

Figure 1. A possible mechanistic and temporal framework for cardiac autonomic neuropathy (CAN) progression in deteriorating metabolic function and the different interdependent pathways contributing to it. Increased caloric intake induces insulin resistance and alterations in gut microbiota (GM). The resulting hyperinsulinemia and dysbiosis could precipitate adipose inflammation directly or indirectly through sympatho-vagal imbalance. In this context, nuclear factor kappa B (NF- $\mathrm{B}$ )-induced inflammation results from hypoxia related to perivascular adipose tissue (PVAT) expansion, as well as activation of Toll-like receptors 4 (TLR4) in response to metabolic endotoxemia. Increased proinflammatory sympathetic outflow and diminished anti-inflammatory vagal discharge could further contribute to PVAT inflammation. Later, metabolic decompensation results in $\beta$-cell depletion, hyperglycemia, and advanced glycated end products (AGEs), which in turn aggravate the pre-existing localized inflammation, triggering wider changes. Several markers of systemic inflammation have been shown to be associated with deterioration of cardiac autonomic control. Disruption of blood-brain barrier function associated with dysbiosis and systemic inflammation promotes spillage of proinflammatory cytokines to regions of the central nervous system resulting in neuroinflammation and further cardiac autonomic and cardiovascular (CV) dysfunction.

It remains questionable, however, in the light of primary autonomic dysfunction characteristic of T2D, whether adipose inflammation results in CAN or is a consequence of it. A longitudinal study on independent population cohorts established consistent associations between autonomic activity and inflammatory maskers (CRP and IL-6). Specifically, the study revealed that baseline vagal activity predicted the levels of inflammatory markers on follow-up. It is worth mentioning, however, that this study was not done exclusively on diabetic patients [106]. In fact, a longitudinal study in T2D patients revealed an independent negative association between baseline IL-1 receptor antagonist and HR, 
indicating a possible role for IL-1 in the pathogenesis of CAN [98]. Additionally, it is important to present sympathetic dysfunction as a possible contributing mechanism to T2D inflammatory processes especially with the presence of evidence regarding the involvement of the sympathetic nervous system in the regulation of immune responses $[107,108]$.

\section{Relationship between Gut Microbiota and Autonomic Dysfunction in Metabolic Diseases}

Indeed, autonomic control is affected by the GM population in a bidirectional association [109]. The vagus nerve is known to mediate the relationship between the gut and the brain [109]. As vagal nerve afferent fibers are capable of sensing GM metabolites and transducing sensory messages to the central nervous system, the vagus can additionally affect the profile of the GM through its cholinergic anti-inflammatory efferents. As such, conditions associated with altered or reduced vagal tone have been shown to be characterized by dysbiosis [109].

Moreover, an increase in the sympathetic outflow has been reported to be associated with reduced gut integrity and increased permeability by compromising tight junction proteins, promoting a proinflammatory state alongside dysbiosis [66]. In the spontaneously hypertensive rat model, it was reported that these changes initiate an elevation in BP [110]. This was supported by using acetylcholine esterase (ACE) inhibitors in those rats, which tempered sympathetic activation, lowered BP and improved gut integrity, and promoted eubiosis [110]. On the other hand, the state of dysbiosis and its proinflammatory byproducts centrally activate the sympathetic nervous system, which induces HTN and a proinflammatory state [65]. Another pathway is through the lack of sympathetic nervous system suppression metabolites. Interestingly, some bifidobacteria, found to be reduced in hypertensive patients, produce $\gamma$-aminobutyric acid, which has a sympatholytic effect [65]. Furthermore, some bacteria can produce serotonin, norepinephrine, which are prohypertensive and proatherogenic [65]. Indeed, some lactobacilli that are altered in dysbiosis can activate the vagal tone and its subsequent anti-inflammatory outcomes [65].

Hence, dysbiosis was found to promote autonomic imbalance and induce a sympatho-excitatory state, which has been long recognized to be proinflammatory $[65,111]$. Noteworthy, dysbiosis can activate RAAS [112,113], which in turn can promote vascular dysfunction via the angiotensin II (Ang II) pathway $[66,113,114]$. In this regard, Ang II-mediated HTN was not attained in a germ-free mouse model [115]. Furthermore, SCFAs were found to be protective against Ang II-induced BP and RAAS activation [115]. Alternatively, the angiotensin-converting enzyme 2/angiotensin 1-7 axis has been suggested to attenuate immune responses via modulation of GM composition [116]. Hence, it can be proposed that changes in the RAAS system such as those seen in the metabolic syndrome and T2D can predict inflammatory responses through the GM. Another phenomenon through which dysbiosis could alter cardiac autonomic control in T2D patients and promote sympathetic predominance is a fatty liver. Indeed, elevated liver fat has been associated with reduced cardiovagal tone and BRS in T2D [117]. While evidence exists to link changes in GM in metabolic disorders to adipose tissue and systemic inflammation and to possible alteration of cardiac autonomic function under the same circumstances, it is not clear how these factors interplay in the temporal framework for the development and progression of T2D.

\section{CAN as a Possible Mediator of the Impact of Meta-inflammation on Cardiovascular Disease in the Continuum from Prediabetes to T2D}

Current research provides links among the change in inflammatory profile along the continuum of the disease, the severity of CAN, and the risk of cardiovascular disease $[17,118]$. In particular, studies show than the progression of CAN manifestations exist at the crossroad between inflammatory processes and cardiovascular complications. A study by Grossmann et al. identified different patterns of change in biomarkers of immune and inflammatory responses along the continuum of the diabetes [17]. In particular, they differentiated between biomarkers, the levels of which gradually increase with worsening of metabolic control from normoglycemia, prediabetes, to T2D (e.g., IL-1R antagonist, 
IL-18, and monocytes), and others exclusively increasing in the progression to subclinical disease i.e., prediabetes (such as CRP). Importantly, such changes coincide with the natural history of CAN in T2D, whereby an initial increase in CRP marks an early reduction in cardiovagal tone characteristic of the prediabetic stage [77]. Later, a delayed systemic decrease in IL-1R antagonist along with a concomitant increase in neuroinflammatory IL-18 comes in parallel with further blunting of parasympathetic function on the onset of T2D, as previously described [97,98]. Interestingly, there was a gradual increase in cardiovascular risk factors and comorbidities from normoglycemia to prediabetes to T2D [17]. In parallel, a recent 6 year follow-up study showed that the severity of CAN is predictive of major adverse cardiovascular events [118]. In particular, an increase in cardiac autonomic composite score is accompanied by an elevated risk of cardiovascular death, nonfatal myocardial infarction, and nonfatal stroke. This provides evidence that meta-inflammation promotes cardiovascular complications possibly through worsening cardiac autonomic control. Hence, it becomes necessary to develop therapeutic interventions targeted at reducing inflammatory load in an attempt to reduce the burden of CAN and its associated cardiovascular risk.

\section{Therapeutic Interventions to Ameliorate CAN in T2D}

Studies investigating the ameliorative effect of antidiabetic treatment, with drugs such as metformin and pioglitazone, on CAN revealed that it is mediated by their anti-inflammatory properties $[99,119,120]$. In fact, metformin was demonstrated to improve cardiac autonomic function in nondiabetic-related inflammatory states such as hypertension [121]. Metformin treatment alleviated not only vascular inflammation by reducing the tissue expression of cyclooxygenase 2 (COX2) and NADPH oxidase 2 (NOX2), but also systemic inflammation demonstrated by a drop in TNF- $\alpha$ levels [121]. Treatment with metformin or pioglitazone was shown consistently to reduce adipose tissue inflammation and oxidative stress not only in cardiovascular tissues, but also in several brain regions including the brainstem at different stages of metabolic disease including prediabetes and T2D [84,99,100,102]. In these studies, either drug produced the desirable effects in nonhypoglycemic doses. In fact, the modulatory effect on adipose inflammation and CAN cannot be attributed to a reduction in blood glucose levels even in T2D. Indeed, tight glycemic control of T2D rats did not reduce markers of systemic inflammation and failed to reverse signs of CAN [84], potentially ascribing the beneficial effects of metformin and pioglitazone to pleiotropic effects. Specifically, their anti-inflammatory properties mediated by the activation of $5^{\prime}$ adenosine monophosphate-activated protein kinase and peroxisome proliferator-activated receptor gamma, respectively, were shown to ameliorate adipose tissue inflammation triggered by increased caloric intake [122-124]. Additionally, $5^{\prime}$ adenosine monophosphate-activated protein kinase activation has been implicated in desirable effects on autophagy with specific positive effects on diabetic neuropathy $[84,125]$.

Along the same lines, drugs with a presumably neutral effect on blood glucose but proven to curb inflammation, such as minocycline, were shown to bring about an improvement in diabetic CAN [126]. Interestingly, minocycline has been shown to be an inhibitor of microglial activation, providing further evidence that central neuroinflammation might be involved in the pathogenesis of CAN in metabolic disorders. Significantly, minocycline was shown to normalize the alteration in GM and the ensuing proinflammatory gene expression resulting from high-fat diet feeding in rats [127] further emphasizing the interplay among these pathways in the development of CAN in the context of metabolic dysfunction. Similarly, cardiac autonomic manifestations in T2D normotensive patients were shown to favorably respond to ACE inhibition [128-130]. Treatment with an ACE inhibitor was shown to curb systemic inflammation and oxidative stress, as a consequence of normalized sympathetic overactivity, demonstrated by myocardial adrenergic innervation in this patient population [128]. Interestingly, not only could this observation be attributed to improved vascular elasticity [131] due to a reduced vascular inflammatory and oxidative milieu and, thus, enhanced BRS, but it could also be explained in light of an effect on adipose tissue inflammation. Indeed, ACE activity and angiotensin-II production are upregulated in metabolic disorders involving adipose tissue expansion 
and dysfunction [132,133]. Furthermore, the beneficial effect of ACE inhibitors could be related to reducing central inflammatory changes driven by systemic inflammation [12,84]. Moreover, the positive effect seen with Ang II inhibition could possibly be due to the reduction in hs-CRP associated with such a treatment [134], especially in the context of T2D where the levels of hs-CRP demonstrated a correlation with cardiac autonomic function [135].

Lastly, it might seem prudent to develop interventions tailored to reverse adipose tissue inflammation as a possible therapy for CAN. Indeed, such interventions were proposed for various cardiac and vascular disorders associated with metabolic impairment [33]. While the search for such tools is ongoing, simple interventions leading to this outcome might include modification of caloric intake. Indeed, previous research showed that approaches involving caloric restriction and intermittent fasting were associated with an ameliorative effect on both perivascular adipose inflammation and CAN $[99,136]$.

\section{Conclusions}

This review attempted to provide a mechanistic and temporal framework, whereby the progression of low-grade inflammation from being localized in adipose tissue to a more systemic and central fashion parallels and potentially induces CAN deterioration during the natural course of the metabolic insult leading to T2D. Indeed, evidence supports the involvement of pro-oxidative and proinflammatory processes in the pathogenesis of CAN in T2D being adipose, vascular, systemic, and neuronal in nature. These have been shown to be related to hormonal disturbances such as hyperinsulinemia and an overactivation of the RAAS secondary to disease components. Additionally, metabolically induced alterations in GM were suggested to possibly mediate the effect of inflammation on CAN initiation and evolution. A detailed structured examination of these pathways in the future will assist in the development of targeted disease-modifying interventions to halt or reverse the manifestations of CAN in this patient population.

Funding: This work was funded by the Faculty of Medicine at the American University of Beirut, Medical Practice Plan, grant \#320148 to A.F.E. and UAEU Program for Advanced Research, grant number 31S398-UPAR to Y.A.-D.

Conflicts of Interest: The authors declare no conflict of interest.

\section{References}

1. Zoppini, G.; Cacciatori, V.; Raimondo, D.; Gemma, M.; Trombetta, M.; Dauriz, M.; Brangani, C.; Pichiri, I.; Negri, C.; Stoico, V. Prevalence of cardiovascular autonomic neuropathy in a cohort of patients with newly diagnosed type 2 diabetes: The Verona Newly Diagnosed Type 2 Diabetes Study (VNDS). Diabetes Care 2015, 38, 1487-1493. [CrossRef] [PubMed]

2. Kück, J.-L.; Bönhof, G.J.; Strom, A.; Zaharia, O.-P.; Müssig, K.; Szendroedi, J.; Roden, M.; Ziegler, D. Impairment in baroreflex sensitivity in recent-onset type 2 diabetes without progression over 5 years. Diabetes 2020, 69, 1011-1019. [CrossRef] [PubMed]

3. Boulton, A.J.; Vinik, A.I.; Arezzo, J.C.; Bril, V.; Feldman, E.L.; Freeman, R.; Malik, R.A.; Maser, R.E.; Sosenko, J.M.; Ziegler, D. Diabetic neuropathies: A statement by the American Diabetes Association. Diabetes Care 2005, 28, 956-962. [CrossRef] [PubMed]

4. Rolim, L.; Sá, J.; Chacra, A.R.; Dib, S.A. Diabetic cardiovascular autonomic neuropathy: Risk factors, clinical impact and early diagnosis. Arq. Bras. Cardiol. 2008, 90, e24-e31. [CrossRef] [PubMed]

5. Goldberger, J.J; Arora, R.; Buckley, U.; Shivkumar, K. Autonomic nervous system dysfunction: JACC focus seminar. J. Am. Coll. Cardiol. 2019, 73, 1189-1206. [CrossRef]

6. Ruiz, J.; Monbaron, D.; Parati, G.; Perret, S.; Haesler, E.; Danzeisen, C.; Hayoz, D. Diabetic neuropathy is a more important determinant of baroreflex sensitivity than carotid elasticity in type 2 diabetes. Hypertension 2005, 46, 162-167. [CrossRef]

7. Cseh, D.; Climie, R.E.; Offredo, L.; Guibout, C.; Thomas, F.; Zanoli, L.; Danchin, N.; Sharman, J.E.; Laurent, S.; Jouven, X.; et al. Type 2 Diabetes Mellitus Is Independently Associated With Decreased Neural Baroreflex Sensitivity: The Paris Prospective Study III. Arterioscler. Thromb. Vasc. Biol. 2020, 40, 1420-1428. [CrossRef] 
8. Wu, J.-S.; Lu, F.-H.; Yang, Y.-C.; Chang, S.-H.; Huang, Y.-H.; Chen, J.-J.J.; Chang, C.-J. Impaired baroreflex sensitivity in subjects with impaired glucose tolerance, but not isolated impaired fasting glucose. Acta Diabetol. 2014, 51, 535-541. [CrossRef]

9. Levick, J. Cardiovascular Receptors, Reflexes and Central Control. An Introduction to Cardiovascular Physiology, 4th ed.; Hodder Arnold Publication: London, UK, 2003; pp. 279-296.

10. Aicher, S.A.; Milner, T.A.; Pickel, V.M.; Reis, D.J. Anatomical substrates for baroreflex sympathoinhibition in the rat. Brain Res. Bull. 2000, 51, 107-110. [CrossRef]

11. Lin, I.C.; Wu, C.-W.; Tain, Y.-L.; Chen, I.-C.; Hung, C.-Y.; Wu, K.L. High fructose diet induces early mortality via autophagy factors accumulation in the rostral ventrolateral medulla as ameliorated by pioglitazone. J. Nutr. Biochem. 2019, 69, 87-97. [CrossRef]

12. Speretta, G.F.; Ruchaya, P.J.; Delbin, M.A.; Melo, M.R.; Li, H.; Menani, J.V.; Sumners, C.; Colombari, E.; Bassi, M.; Colombari, D.S. Importance of AT1 and AT2 receptors in the nucleus of the solitary tract in cardiovascular responses induced by a high-fat diet. Hypertens. Res. 2019, 42, 439-449. [CrossRef]

13. Sheng, X.; Dan, Y.; Dai, B.; Guo, J.; Ji, H.; Zhang, X.; Xie, Z.; Song, S.; Pan, Q.; Wang, J. Knockdown the P2X3 receptor in the stellate ganglia of rats relieved the diabetic cardiac autonomic neuropathy. Neurochem. Int. 2018, 120, 206-212. [CrossRef] [PubMed]

14. Wu, B.; Sheng, X.; Xu, Z.; Zhang, Y.; Dan, Y.; Guo, J.; Peng, H.; Liang, S.; Li, G. Osthole relieves diabetics cardiac autonomic neuropathy associated with $\mathrm{P} 2 \mathrm{X} 3$ receptor in ratstellate ganglia. Brain Res. Bull. 2020, 157, 90-99. [CrossRef] [PubMed]

15. Sheng, X.; Wang, J.; Guo, J.; Xu, Y.; Jiang, H.; Zheng, C.; Xu, Z.; Zhang, Y.; Che, H.; Liang, S. Effects of baicalin on diabetic cardiac autonomic neuropathy mediated by the P2Y12 receptor in rat stellate ganglia. Cell. Physiol. Biochem. 2018, 46, 986-998. [CrossRef] [PubMed]

16. Donath, M.Y. Targeting inflammation in the treatment of type 2 diabetes: Time to start. Nat. Rev. Drug Discov. 2014, 13, 465-476. [CrossRef]

17. Grossmann, V.; Schmitt, V.H.; Zeller, T.; Panova-Noeva, M.; Schulz, A.; Laubert-Reh, D.; Juenger, C.; Schnabel, R.B.; Abt, T.G.; Laskowski, R. Profile of the immune and inflammatory response in individuals with prediabetes and type 2 diabetes. Diabetes Care 2015, 38, 1356-1364. [CrossRef]

18. Festa, A.; D’Agostino, R., Jr.; Howard, G.; Mykkanen, L.; Tracy, R.P.; Haffner, S.M. Chronic subclinical inflammation as part of the insulin resistance syndrome: The Insulin Resistance Atherosclerosis Study (IRAS). Circulation 2000, 102, 42-47. [CrossRef]

19. Shoelson, S.E.; Goldfine, A.B. Getting away from glucose: Fanning the flames of obesity-induced inflammation. Nat. Med. 2009, 15, 373-374. [CrossRef]

20. Hotamisligil, G.S. Endoplasmic reticulum stress and the inflammatory basis of metabolic disease. Cell 2010, 140, 900-917. [CrossRef]

21. Cullinan, S.B.; Diehl, J.A. Coordination of ER and oxidative stress signaling: The PERK/Nrf2 signaling pathway. Int. J. Biochem. Cell Biol. 2006, 38, 317-332. [CrossRef]

22. Pedersen, D.J.; Guilherme, A.; Danai, L.V.; Heyda, L.; Matevossian, A.; Cohen, J.; Nicoloro, S.M.; Straubhaar, J.; Noh, H.L.; Jung, D. A major role of insulin in promoting obesity-associated adipose tissue inflammation. Mol. Metab. 2015, 4, 507-518. [CrossRef] [PubMed]

23. Campos, S.; Baumann, H. Insulin is a prominent modulator of the cytokine-stimulated expression of acute-phase plasma protein genes. Mol. Cell. Biol. 1992, 12, 1789-1797. [CrossRef] [PubMed]

24. Ye, J. Emerging role of adipose tissue hypoxia in obesity and insulin resistance. Int. J. Obes. 2009, 33, 54-66. [CrossRef] [PubMed]

25. Kushner, I. Regulation of the acute phase response by cytokines. Perspect. Biol. Med. 1993, 36, 611-622. [CrossRef]

26. Samad, F.; Uysal, K.T.; Wiesbrock, S.M.; Pandey, M.; Hotamisligil, G.S.; Loskutoff, D.J. Tumor necrosis factor $\alpha$ is a key component in the obesity-linked elevation of plasminogen activator inhibitor 1. Proc. Natl. Acad. Sci. USA 1999, 96, 6902-6907. [CrossRef]

27. Cinti, S.; Mitchell, G.; Barbatelli, G.; Murano, I.; Ceresi, E.; Faloia, E.; Wang, S.; Fortier, M.; Greenberg, A.S.; Obin, M.S. Adipocyte death defines macrophage localization and function in adipose tissue of obese mice and humans. J. Lipid Res. 2005, 46, 2347-2355. [CrossRef]

28. Weisberg, S.P.; McCann, D.; Desai, M.; Rosenbaum, M.; Leibel, R.L.; Ferrante, A.W. Obesity is associated with macrophage accumulation in adipose tissue. J. Clin. Investig. 2003, 112, 1796-1808. [CrossRef] 
29. Meier, B.; Radeke, H.; Selle, S.; Younes, M.; Sies, H.; Resch, K.; Habermehl, G. Human fibroblasts release reactive oxygen species in response to interleukin-1 or tumour necrosis factor- $\alpha$. Biochem. J. 1989, 263, 539-545. [CrossRef]

30. Bandeira, D.M.; Da Fonseca, L.J.S.; Guedes, D.S.; Rabelo, L.A.; Goulart, M.O.; Vasconcelos, S.M.L. Oxidative stress as an underlying contributor in the development of chronic complications in diabetes mellitus. Int. J. Mol. Sci. 2013, 14, 3265-3284. [CrossRef]

31. Downs, C.A.; Faulkner, M.S. Toxic stress, inflammation and symptomatology of chronic complications in diabetes. World J. Diabetes 2015, 6, 554. [CrossRef]

32. Pliquett, R.; Fasshauer, M.; Blüher, M.; Paschke, R. Neurohumoral stimulation in type-2-diabetes as an emerging disease concept. Cardiovasc. Diabetol. 2004, 3, 1-8. [CrossRef] [PubMed]

33. Rafeh, R.; Viveiros, A.; Oudit, G.Y.; El-Yazbi, A.F. Targeting perivascular and epicardial adipose tissue inflammation: Therapeutic opportunities for cardiovascular disease. Clin. Sci. 2020, 134, 827-851. [CrossRef] [PubMed]

34. Etchegoyen, M.; Nobile, M.H.; Baez, F.; Posesorski, B.; González, J.; Lago, N.; Milei, J.; Otero-Losada, M. Metabolic syndrome and neuroprotection. Front. Neurosci. 2018, 12, 196. [CrossRef] [PubMed]

35. Pop-Busui, R.; Ang, L.; Holmes, C.; Gallagher, K.; Feldman, E.L. Inflammation as a therapeutic target for diabetic neuropathies. Curr. Diabetes Rep. 2016, 16, 29. [CrossRef]

36. Mauro, C.; De Rosa, V.; Marelli-Berg, F.; Solito, E. Metabolic syndrome and the immunological affair with the blood-brain barrier. Front. Immunol. 2015, 5, 677. [CrossRef]

37. Van Dyken, P.; Lacoste, B. Impact of Metabolic Syndrome on Neuroinflammation and the Blood-Brain Barrier. Front. Neurosci. 2018, 12. [CrossRef]

38. Thomsen, M.S.; Routhe, L.J.; Moos, T. The vascular basement membrane in the healthy and pathological brain. J. Cereb. Blood Flow Metab. 2017, 37, 3300-3317. [CrossRef]

39. Muriach, M.; Flores-Bellver, M.; Romero, F.J.; Barcia, J.M. Diabetes and the brain: Oxidative stress, inflammation, and autophagy. Oxid. Med. Cell. Longev. 2014, 2014, 102158. [CrossRef]

40. Fisher-Wellman, K.H.; Neufer, P.D. Linking mitochondrial bioenergetics to insulin resistance via redox biology. Trends Endocrinol. Metab. 2012, 23, 142-153. [CrossRef]

41. Sifuentes-Franco, S.; Pacheco-Moisés, F.P.; Rodríguez-Carrizalez, A.D.; Miranda-Díaz, A.G. The role of oxidative stress, mitochondrial function, and autophagy in diabetic polyneuropathy. J. Diabetes Res. 2017, 2017, 1673081. [CrossRef]

42. Román-Pintos, L.M.; Villegas-Rivera, G.; Rodríguez-Carrizalez, A.D.; Miranda-Díaz, A.G.; Cardona-Muñoz, E.G. Diabetic polyneuropathy in type 2 diabetes mellitus: Inflammation, oxidative stress, and mitochondrial function. J. Diabetes Res. 2016, 2016, 3425617. [CrossRef] [PubMed]

43. Everard, A.; Cani, P.D. Diabetes, obesity and gut microbiota. Best Pract. Res. Clin. Gastroenterol. 2013, 27, 73-83. [CrossRef] [PubMed]

44. Tilg, H.; Zmora, N.; Adolph, T.E.; Elinav, E. The intestinal microbiota fuelling metabolic inflammation. Nat. Rev. Immunol. 2019, 1-15. [CrossRef] [PubMed]

45. Jonsson, A.L.; Bäckhed, F. Role of gut microbiota in atherosclerosis. Nat. Rev. Cardiol. 2017, 14, 79. [CrossRef] [PubMed]

46. Muscogiuri, G.; Cantone, E.; Cassarano, S.; Tuccinardi, D.; Barrea, L.; Savastano, S.; Colao, A. Gut microbiota: A new path to treat obesity. Int. J. Obes. Suppl. 2019, 9, 10-19. [CrossRef]

47. Cani, P.D.; Van Hul, M.; Lefort, C.; Depommier, C.; Rastelli, M.; Everard, A. Microbial regulation of organismal energy homeostasis. Nat. Metab. 2019, 1, 34. [CrossRef]

48. Lu, Y.-C.; Yeh, W.-C.; Ohashi, P.S. LPS/TLR4 signal transduction pathway. Cytokine 2008, 42, $145-151$. [CrossRef]

49. Caesar, R.; Tremaroli, V.; Kovatcheva-Datchary, P.; Cani, P.D.; Bäckhed, F. Crosstalk between gut microbiota and dietary lipids aggravates WAT inflammation through TLR signaling. Cell Metab. 2015, 22, 658-668. [CrossRef]

50. Takeuchi, O.; Hoshino, K.; Kawai, T.; Sanjo, H.; Takada, H.; Ogawa, T.; Takeda, K.; Akira, S. Differential roles of TLR2 and TLR4 in recognition of gram-negative and gram-positive bacterial cell wall components. Immunity 1999, 11, 443-451. [CrossRef] 
51. Cani, P.D.; Bibiloni, R.; Knauf, C.; Waget, A.; Neyrinck, A.M.; Delzenne, N.M.; Burcelin, R. Changes in gut microbiota control metabolic endotoxemia-induced inflammation in high-fat diet-induced obesity and diabetes in mice. Diabetes 2008, 57, 1470-1481. [CrossRef]

52. Laugerette, F.; Vors, C.; Géloën, A.; Chauvin, M.-A.; Soulage, C.; Lambert-Porcheron, S.; Peretti, N.; Alligier, M.; Burcelin, R.; Laville, M. Emulsified lipids increase endotoxemia: Possible role in early postprandial low-grade inflammation. J. Nutr. Biochem. 2011, 22, 53-59. [CrossRef] [PubMed]

53. Ghoshal, S.; Witta, J.; Zhong, J.; De Villiers, W.; Eckhardt, E. Chylomicrons promote intestinal absorption of lipopolysaccharides. J. Lipid Res. 2009, 50, 90-97. [CrossRef] [PubMed]

54. Żółkiewicz, J.; Marzec, A.; Ruszczyński, M.; Feleszko, W. Postbiotics-A Step Beyond Pre-and Probiotics. Nutrients 2020, 12, 2189. [CrossRef] [PubMed]

55. Gibson, G.R.; Roberfroid, M.B. Dietary Modulation of the Human Colonic Microbiota: Introducing the Concept of Prebiotics. J. Nutr. 1995, 125, 1401-1412. [CrossRef] [PubMed]

56. Ohland, C.L.; MacNaughton, W.K. Probiotic bacteria and intestinal epithelial barrier function. Am. J. Physiol.-Gastrointest. Liver Physiol. 2010, 298, G807-G819. [CrossRef] [PubMed]

57. Pham, V.T.; Seifert, N.; Richard, N.; Raederstorff, D.; Steinert, R.E.; Prudence, K.; Mohajeri, M.H. The effects of fermentation products of prebiotic fibres on gut barrier and immune functions in vitro. PeerJ 2018, 6, e5288. [CrossRef]

58. Gao, J.; Li, Y.; Wan, Y.; Hu, T.; Liu, L.; Yang, S.; Gong, Z.; Zeng, Q.; Wei, Y.; Yang, W.; et al. A Novel Postbiotic From Lactobacillus rhamnosus GG With a Beneficial Effect on Intestinal Barrier Function. Front. Microbiol. 2019, 10, 477. [CrossRef]

59. Cani, P.D.; Amar, J.; Iglesias, M.A.; Poggi, M.; Knauf, C.; Bastelica, D.; Neyrinck, A.M.; Fava, F.; Tuohy, K.M.; Chabo, C. Metabolic endotoxemia initiates obesity and insulin resistance. Diabetes 2007, 56, 1761-1772. [CrossRef]

60. Canfora, E.E.; Jocken, J.W.; Blaak, E.E. Short-chain fatty acids in control of body weight and insulin sensitivity. Nat. Rev. Endocrinol. 2015, 11, 577. [CrossRef]

61. Wilkins, L.J.; Monga, M.; Miller, A.W. Defining Dysbiosis for a Cluster of Chronic Diseases. Sci. Rep. 2019, 9, 1-10. [CrossRef]

62. Kim, K.-A.; Gu, W.; Lee, I.-A.; Joh, E.-H.; Kim, D.-H. High fat diet-induced gut microbiota exacerbates inflammation and obesity in mice via the TLR4 signaling pathway. PLoS ONE 2012, 7, e47713. [CrossRef] [PubMed]

63. Kappel, B.A.; Federici, M. Gut microbiome and cardiometabolic risk. Rev. Endocr. Metab. Disord. 2019, 20, 399-406. [CrossRef] [PubMed]

64. Amedei, A.; Morbidelli, L. Circulating metabolites originating from gut microbiota control endothelial cell function. Molecules 2019, 24, 3992. [CrossRef] [PubMed]

65. Onal, E.M.; Afsar, B.; Covic, A.; Vaziri, N.D.; Kanbay, M. Gut microbiota and inflammation in chronic kidney disease and their roles in the development of cardiovascular disease. Hypertens. Res. 2019, 42, 123-140. [CrossRef]

66. Peng, J.; Xiao, X.; Hu, M.; Zhang, X. Interaction between gut microbiome and cardiovascular disease. Life Sci. 2018, 214, 153-157. [CrossRef]

67. Bradley, D.; Liu, J.; Blaszczak, A.; Wright, V.; Jalilvand, A.; Needleman, B.; Noria, S.; Renton, D.; Hsueh, W. Adipocyte DIO2 Expression Increases in Human Obesity but Is Not Related to Systemic Insulin Sensitivity. J. Diabetes Res. 2018, 2018, 2464652. [CrossRef]

68. Nemet, I.; Saha, P.P.; Gupta, N.; Zhu, W.; Romano, K.A.; Skye, S.M.; Cajka, T.; Mohan, M.L.; Li, L.; Wu, Y. A cardiovascular disease-linked gut microbial metabolite acts via adrenergic receptors. Cell 2020, 180, 862-877.e822. [CrossRef]

69. Brial, F.; Le Lay, A.; Dumas, M.-E.; Gauguier, D. Implication of gut microbiota metabolites in cardiovascular and metabolic diseases. Cell. Mol. Life Sci. 2018, 75, 3977-3990. [CrossRef]

70. Meyer, K.A.; Bennett, B.J. Diet and gut microbial function in metabolic and cardiovascular disease risk. Curr. Diabetes Rep. 2016, 16, 93. [CrossRef]

71. Schiattarella, G.G.; Sannino, A.; Esposito, G.; Perrino, C. Diagnostics and therapeutic implications of gut microbiota alterations in cardiometabolic diseases. Trends Cardiovasc. Med. 2019, 29, 141-147. [CrossRef] 
72. Geurts, L.; Neyrinck, A.M.; Delzenne, N.M.; Knauf, C.; Cani, P.D. Gut microbiota controls adipose tissue expansion, gut barrier and glucose metabolism: Novel insights into molecular targets and interventions using prebiotics. Benef. Microbes 2014, 5, 3-17. [CrossRef] [PubMed]

73. Ziegler, D.; Strom, A.; Bönhof, G.; Püttgen, S.; Bódis, K.; Burkart, V.; Müssig, K.; Szendroedi, J.; Markgraf, D.F.; Roden, M. Differential associations of lower cardiac vagal tone with insulin resistance and insulin secretion in recently diagnosed type 1 and type 2 diabetes. Metabolism 2018, 79, 1-9. [CrossRef] [PubMed]

74. Hong, L.-Z.; Hsieh, P.-S. Hyperinsulinemia instead of insulin resistance induces baroreflex dysfunction in chronic insulin-infused rats. Am. J. Hypertens. 2007, 20, 451-458. [CrossRef] [PubMed]

75. Xu, W.; Zhu, Y.; Yang, X.; Deng, H.; Yan, J.; Lin, S.; Yang, H.; Chen, H.; Weng, J. Glycemic variability is an important risk factor for cardiovascular autonomic neuropathy in newly diagnosed type 2 diabetic patients. Int. J. Cardiol. 2016, 215, 263-268. [CrossRef]

76. Ceriello, A.; Esposito, K.; Piconi, L.; Ihnat, M.A.; Thorpe, J.E.; Testa, R.; Boemi, M.; Giugliano, D. Oscillating glucose is more deleterious to endothelial function and oxidative stress than mean glucose in normal and type 2 diabetic patients. Diabetes 2008, 57, 1349-1354. [CrossRef]

77. Bhati, P.; Alam, R.; Moiz, J.A.; Hussain, M.E. Subclinical inflammation and endothelial dysfunction are linked to cardiac autonomic neuropathy in type 2 diabetes. J. Diabetes Metab. Disord. 2019, 18, 419-428. [CrossRef]

78. Alaaeddine, R.; Elkhatib, M.A.; Mroueh, A.; Fouad, H.; Saad, E.I.; El-Sabban, M.E.; Plane, F.; El-Yazbi, A.F. Impaired endothelium-dependent hyperpolarization underlies endothelial dysfunction during early metabolic challenge: Increased ROS generation and possible interference with NO function. J. Pharmacol. Exp. Ther. 2019, 371, 567-582. [CrossRef]

79. Alaaeddine, R.A.; Mroueh, A.; Gust, S.; Eid, A.H.; Plane, F.; El-Yazbi, A.F. Impaired cross-talk between $\mathrm{NO}$ and hyperpolarization in myoendothelial feedback: A novel therapeutic target in early endothelial dysfunction of metabolic disease. Curr. Opin. Pharmacol. 2019, 45, 33-41. [CrossRef]

80. Matsutani, D.; Sakamoto, M.; Iuchi, H.; Minato, S.; Suzuki, H.; Kayama, Y.; Takeda, N.; Horiuchi, R.; Utsunomiya, K. Glycemic variability in continuous glucose monitoring is inversely associated with baroreflex sensitivity in type 2 diabetes: A preliminary report. Cardiovasc. Diabetol. 2018, 17, 36. [CrossRef]

81. Tarvainen, M.P.; Laitinen, T.P.; Lipponen, J.A.; Cornforth, D.J.; Jelinek, H.F. Cardiac autonomic dysfunction in type 2 diabetes-effect of hyperglycemia and disease duration. Front. Endocrinol. 2014, 5, 130. [CrossRef]

82. Verma, S.; Alam, R.; Ahmad, I.; Singla, D.; Ali, K.; Hussain, M.E. Effect of glycemic control and disease duration on cardiac autonomic function and oxidative stress in type 2 diabetes mellitus. J. Diabetes Metab. Disord. 2018, 17, 149-158. [CrossRef]

83. Vinagre, I.; Sánchez-Quesada, J.L.; Sánchez-Hernández, J.; Santos, D.; Ordoñez-Llanos, J.; De Leiva, A.; Pérez, A. Inflammatory biomarkers in type 2 diabetic patients: Effect of glycemic control and impact of LDL subfraction phenotype. Cardiovasc. Diabetol. 2014, 13, 1-7. [CrossRef] [PubMed]

84. Bakkar, N.-M.Z.; Mougharbil, N.; Mroueh, A.; Kaplan, A.; Eid, A.H.; Fares, S.; Zouein, F.A.; El-Yazbi, A.F. Worsening baroreflex sensitivity on progression to type 2 diabetes: Localized vs. systemic inflammation and role of antidiabetic therapy. Am. J. Physiol.-Endocrinol. Metab. 2020, 319, E835-E851. [CrossRef] [PubMed]

85. Warram, J.H.; Martin, B.C.; Krolewski, A.S.; Soeldner, J.S.; Kahn, C.R. Slow glucose removal rate and hyperinsulinemia precede the development of type II diabetes in the offspring of diabetic parents. Ann. Intern. Med. 1990, 113, 909-915. [CrossRef] [PubMed]

86. Angelis, K.D.; Senador, D.D.; Mostarda, C.; Irigoyen, M.C.; Morris, M. Sympathetic overactivity precedes metabolic dysfunction in a fructose model of glucose intolerance in mice. Am. J. Physiol. Regul. Integr. Comp. Physiol. 2012, 302, R950-R957. [CrossRef] [PubMed]

87. Low, P.A.; Walsh, J.; Huang, C.; McLeod, J. The sympathetic nervous system in diabetic neuropathy: A clinical and pathological study. Brain 1975, 98, 341-356. [CrossRef] [PubMed]

88. Sacre, J.W.; Franjic, B.; Jellis, C.L.; Jenkins, C.; Coombes, J.S.; Marwick, T.H. Association of cardiac autonomic neuropathy with subclinical myocardial dysfunction in type 2 diabetes. JACC Cardiovasc. Imaging 2010, 3, 1207-1215. [CrossRef] [PubMed]

89. Thackeray, J.T.; Radziuk, J.; Harper, M.-E.; Suuronen, E.J.; Ascah, K.J.; Beanlands, R.S.; DaSilva, J.N. Sympathetic nervous dysregulation in the absence of systolic left ventricular dysfunction in a rat model of insulin resistance with hyperglycemia. Cardiovasc. Diabetol. 2011, 10, 75. [CrossRef] 
90. Sleight, P.; La Rovere, M.T.; Mortara, A.; Pinna, G.; Maestri, R.; Leuzzi, S.; Bianchini, B.; Tavazzi, L.; Bernardi, L. Physiology and pathophysiology of heart rate and blood pressure variability in humans: Is power spectral analysis largely an index of baroreflex gain? Clin. Sci. 1995, 88, 103-109. [CrossRef]

91. Mellitus, D. Diagnosis and classification of diabetes mellitus. Diabetes Care 2005, 28, S5-S10.

92. Poliakova, N.; Després, J.-P.; Bergeron, J.; Alméras, N.; Tremblay, A.; Poirier, P. Influence of obesity indices, metabolic parameters and age on cardiac autonomic function in abdominally obese men. Metabolism 2012, 61, 1270-1279. [CrossRef] [PubMed]

93. Ellulu, M.S.; Khaza'ai, H.; Rahmat, A.; Patimah, I.; Abed, Y. Obesity can predict and promote systemic inflammation in healthy adults. Int. J. Cardiol. 2016, 215, 318-324. [CrossRef] [PubMed]

94. Kurajoh, M.; Koyama, H.; Kadoya, M.; Naka, M.; Miyoshi, A.; Kanzaki, A.; Kakutani-Hatayama, M.; Okazaki, H.; Shoji, T.; Moriwaki, Y. Plasma leptin level is associated with cardiac autonomic dysfunction in patients with type 2 diabetes: HSCAA study. Cardiovasc. Diabetol. 2015, 14, 117. [CrossRef] [PubMed]

95. Grigoropoulou, P.; Eleftheriadou, I.; Zoupas, C.; Makrilakis, K.; Papassotiriou, I.; Margeli, A.; Perrea, D.; Katsilambros, N.; Tentolouris, N. Effect of atorvastatin on baroreflex sensitivity in subjects with type 2 diabetes and dyslipidaemia. Diabetes Vasc. Dis. Res. 2014, 11, 26-33. [CrossRef] [PubMed]

96. Lieb, D.C.; Parson, H.K.; Mamikunian, G.; Vinik, A.I. Cardiac autonomic imbalance in newly diagnosed and established diabetes is associated with markers of adipose tissue inflammation. Exp. Diabetes Res. 2012, 2012, 878760. [CrossRef]

97. Herder, C.; Schamarek, I.; Nowotny, B.; Carstensen-Kirberg, M.; Straßburger, K.; Nowotny, P.; Kannenberg, J.M.; Strom, A.; Püttgen, S.; Müssig, K. Inflammatory markers are associated with cardiac autonomic dysfunction in recent-onset type 2 diabetes. Heart 2017, 103, 63-70. [CrossRef]

98. Hansen, C.S.; Vistisen, D.; Jørgensen, M.E.; Witte, D.R.; Brunner, E.J.; Tabák, A.G.; Kivimäki, M.; Roden, M.; Malik, M.; Herder, C. Adiponectin, biomarkers of inflammation and changes in cardiac autonomic function: Whitehall II study. Cardiovasc. Diabetol. 2017, 16, 153. [CrossRef]

99. Al-Assi, O.; Ghali, R.; Mroueh, A.; Kaplan, A.; Mougharbil, N.; Eid, A.H.; Zouein, F.A.; El-Yazbi, A.F. Cardiac autonomic neuropathy as a result of mild hypercaloric challenge in absence of signs of diabetes: Modulation by antidiabetic drugs. Oxid. Med. Cell. Longev. 2018, 2018, 9389784. [CrossRef]

100. Elkhatib, M.A.; Mroueh, A.; Rafeh, R.W.; Sleiman, F.; Fouad, H.; Saad, E.I.; Fouda, M.A.; Elgaddar, O.; Issa, K.; Eid, A.H. Amelioration of perivascular adipose inflammation reverses vascular dysfunction in a model of nonobese prediabetic metabolic challenge: Potential role of antidiabetic drugs. Transl. Res. 2019, 214, 121-143. [CrossRef]

101. Rutkowsky, J.M.; Lee, L.L.; Puchowicz, M.; Golub, M.S.; Befroy, D.E.; Wilson, D.W.; Anderson, S.; Cline, G.; Bini, J.; Borkowski, K. Reduced cognitive function, increased blood-brain-barrier transport and inflammatory responses, and altered brain metabolites in LDLr-/-and C57BL/6 mice fed a western diet. PLoS ONE 2018, 13, e0191909. [CrossRef]

102. Fakih, W.; Mroueh, A.; Salah, H.; Eid, A.H.; Obeid, M.; Kobeissy, F.; Darwish, H.; El-Yazbi, A.F. Dysfunctional cerebrovascular tone contributes to cognitive impairment in a non-obese rat model of prediabetic challenge: Role of suppression of autophagy and modulation by anti-diabetic drugs. Biochem. Pharmacol. 2020, 178, 114041. [CrossRef] [PubMed]

103. Takagishi, M.; Waki, H.; Bhuiyan, M.E.; Gouraud, S.S.; Kohsaka, A.; Cui, H.; Yamazaki, T.; Paton, J.F.; Maeda, M. IL-6 microinjected in the nucleus tractus solitarii attenuates cardiac baroreceptor reflex function in rats. Am. J. Physiol. Regul. Integr. Comp. Physiol. 2010, 298, R183-R190. [CrossRef] [PubMed]

104. Srinivasan, S.; Stevens, M.J.; Sheng, H.; Hall, K.E.; Wiley, J.W. Serum from patients with type 2 diabetes with neuropathy induces complement-independent, calcium-dependent apoptosis in cultured neuronal cells. J. Clin. Investig. 1998, 102, 1454-1462. [CrossRef] [PubMed]

105. Towns, R.; Kabeya, Y.; Yoshimori, T.; Guo, C.; Shangguan, Y.; Hong, S.; Kaplan, M.; Klionsky, D.J.; Wiley, J.W. Sera from patients with type 2 diabetes and neuropathy induce autophagy and colocalization with mitochondria in SY5Y cells. Autophagy 2005, 1, 163-170. [CrossRef] [PubMed]

106. Hu, M.X.; Lamers, F.; Neijts, M.; Willemsen, G.; De Geus, E.J.; Penninx, B.W. Bidirectional prospective associations between cardiac autonomic activity and inflammatory markers. Psychosom. Med. 2018, 80, 475-482. [CrossRef] [PubMed]

107. Maestroni, G.J. Sympathetic nervous system influence on the innate immune response. Ann. N. Y. Acad. Sci. 2006, 1069, 195-207. [CrossRef] 
108. Straub, R.H.; Linde, H.J.; Männel, D.N.; Schölmerich, J.; Falk, W. A bacteria-induced switch of sympathetic effector mechanisms augments local inhibition of TNF- $\alpha$ and IL-6 secretion in the spleen. Faseb J. 2000, 14, 1380-1388.

109. Bonaz, B.; Bazin, T.; Pellissier, S. The vagus nerve at the interface of the microbiota-gut-brain axis. Front. Neurosci. 2018, 12, 49. [CrossRef]

110. Santisteban, M.M.; Qi, Y.; Zubcevic, J.; Kim, S.; Yang, T.; Shenoy, V.; Cole-Jeffrey, C.T.; Lobaton, G.O.; Stewart, D.C.; Rubiano, A. Hypertension-linked pathophysiological alterations in the gut. Circ. Res. 2017, 120, 312-323. [CrossRef]

111. Tanaka, M.; Itoh, H. Hypertension as a metabolic disorder and the novel role of the gut. Curr. Hypertens. Rep. 2019, 21, 63. [CrossRef]

112. Cosola, C.; Rocchetti, M.T.; Sabatino, A.; Fiaccadori, E.; Di Iorio, B.R.; Gesualdo, L. Microbiota issue in CKD: How promising are gut-targeted approaches? J. Nephrol. 2019, 32, 27-37. [CrossRef] [PubMed]

113. Bryniarski, M.A.; Hamarneh, F.; Yacoub, R. The role of chronic kidney disease-associated dysbiosis in cardiovascular disease. Exp. Biol. Med. 2019, 244, 514-525. [CrossRef] [PubMed]

114. Bartolomaeus, H.; Markó, L.; Wilck, N.; Luft, F.C.; Forslund, S.K.; Muller, D.N. Precarious symbiosis between host and microbiome in cardiovascular health. Hypertension 2019, 73, 926-935. [CrossRef] [PubMed]

115. Yang, T.; Richards, E.M.; Pepine, C.J.; Raizada, M.K. The gut microbiota and the brain-gut-kidney axis in hypertension and chronic kidney disease. Nat. Rev. Nephrol. 2018, 14, 442-456. [CrossRef]

116. Oliveira Andrade, J.M.; de Farias Lelis, D.; Mafra, V.; Cota, J. The Angiotensin Converting Enzyme 2 (ACE2), Gut Microbiota, and Cardiovascular Health. Protein Pept. Lett. 2017, 24, 827-832. [CrossRef]

117. Ziegler, D.; Strom, A.; Kupriyanova, Y.; Bierwagen, A.; Bönhof, G.J.; Bódis, K.; Müssig, K.; Szendroedi, J.; Bobrov, P.; Markgraf, D.F. Association of lower cardiovagal tone and baroreflex sensitivity with higher liver fat content early in type 2 diabetes. J. Clin. Endocrinol. Metab. 2018, 103, 1130-1138. [CrossRef]

118. Lai, Y.-R.; Huang, C.-C.; Chang, H.-W.; Chiu, W.-C.; Tsai, N.-W.; Cheng, B.-C.; Chen, J.-F.; Lu, C.-H. Severity of Cardiovascular Autonomic Neuropathy Is a Predictor Associated With Major Adverse Cardiovascular Events in Adults With Type 2 Diabetes Mellitus: A 6-year Follow-up Study. Can. J. Diabetes 2020. [CrossRef]

119. Karagiannis, E.; Pfützner, A.; Forst, T.; Lübben, G.; Roth, W.; Grabellus, M.; Flannery, M.; Schöndorf, T. The IRIS V study: Pioglitazone improves systemic chronic inflammation in patients with type 2 diabetes under daily routine conditions. Diabetes Technol. Ther. 2008, 10, 206-212. [CrossRef]

120. Nerla, R.; Pitocco, D.; Zaccardi, F.; Scalone, G.; Coviello, I.; Mollo, R.; Ghirlanda, G.; Lanza, G.A.; Crea, F. Effect of pioglitazone on systemic inflammation is independent of metabolic control and cardiac autonomic function in patients with type 2 diabetes. Acta Diabetol. 2010, 47, 117-122. [CrossRef]

121. Oliveira, P.W.C.; de Sousa, G.J.; Birocale, A.M.; Gouvêa, S.A.; de Figueiredo, S.G.; de Abreu, G.R.; Bissoli, N.S. Chronic metformin reduces systemic and local inflammatory proteins and improves hypertension-related cardiac autonomic dysfunction. Nutr. Metab. Cardiovasc. Dis. 2020, 30, 274-281. [CrossRef]

122. Bassaganya-Riera, J.; Misyak, S.; Guri, A.J.; Hontecillas, R. PPAR $\gamma$ is highly expressed in F4/80hi adipose tissue macrophages and dampens adipose-tissue inflammation. Cell. Immunol. 2009, 258, 138-146. [CrossRef] [PubMed]

123. Bijland, S.; Mancini, S.J.; Salt, I.P. Role of AMP-activated protein kinase in adipose tissue metabolism and inflammation. Clin. Sci. 2013, 124, 491-507. [CrossRef] [PubMed]

124. AlZaim, I.; Hammoud, S.H.; Al-Koussa, H.; Ghazi, A.; Eid, A.H.; El-Yazbi, A.F. Adipose Tissue Immunomodulation: A Novel Therapeutic Approach in Cardiovascular and Metabolic Diseases. Front. Cardiovasc. Med. 2020, 7, 277. [CrossRef]

125. Madhavi, Y.; Gaikwad, N.; Yerra, V.G.; Kalvala, A.K.; Nanduri, S.; Kumar, A. Targeting AMPK in diabetes and diabetic complications: Energy homeostasis, autophagy and mitochondrial health. Curr. Med. Chem. 2019, 26, 5207-5229. [CrossRef]

126. Syngle, A.; Verma, I.; Krishan, P.; Garg, N.; Syngle, V. Minocycline improves peripheral and autonomic neuropathy in type 2 diabetes: MIND study. Neurol. Sci. 2014, 35, 1067-1073. [CrossRef]

127. Leigh, S.-J.; Kaakoush, N.O.; Westbrook, R.F.; Morris, M.J. Minocycline-induced microbiome alterations predict cafeteria diet-induced spatial recognition memory impairments in rats. Transl. Psychiatry 2020, 10, 92. [CrossRef] 
128. Marketou, M.; Zacharis, E.; Koukouraki, S.; Stathaki, M.; Arfanakis, D.; Kochiadakis, G.; Chlouverakis, G.; Karkavitsas, N.; Vardas, P. Effect of angiotensin-converting enzyme inhibitors on systemic inflammation and myocardial sympathetic innervation in normotensive patients with type 2 diabetes mellitus. J. Hum. Hypertens. 2008, 22, 191-196. [CrossRef]

129. Kontopoulos, A.G.; Athyros, V.G.; Didangelos, T.P.; Papageorgiou, A.A.; Avramidis, M.J.; Mayroudi, M.C.; Karamitsos, D.T. Effect of chronic quinapril administration on heart rate variability in patients with diabetic autonomic neuropathy. Diabetes Care 1997, 20, 355-361. [CrossRef]

130. Didangelos, T.; Tziomalos, K.; Margaritidis, C.; Kontoninas, Z.; Stergiou, I.; Tsotoulidis, S.; Karlafti, E.; Mourouglakis, A.; Hatzitolios, A.I. Efficacy of administration of an angiotensin converting enzyme inhibitor for two years on autonomic and peripheral neuropathy in patients with diabetes mellitus. J. Diabetes Res. 2017, 2017, 6719239. [CrossRef]

131. Manolis, A.J.; Iraklianou, S.; Pittaras, A.; Zairis, M.; Tsioufis, K.; Psaltiras, G.; Psomali, D.; Foussas, S.; Gavras, I.; Gavras, H. Arterial compliance changes in diabetic normotensive patients after angiotensin-converting enzyme inhibition therapy. Am. J. Hypertens. 2005, 18, 18-22. [CrossRef]

132. Yvan-Charvet, L.; Quignard-Boulangé, A. Role of adipose tissue renin-angiotensin system in metabolic and inflammatory diseases associated with obesity. Kidney Int. 2011, 79, 162-168. [CrossRef] [PubMed]

133. Pahlavani, M.; Kalupahana, N.S.; Ramalingam, L.; Moustaid-Moussa, N. Regulation and Functions of the Renin-Angiotensin System in White and Brown Adipose Tissue. Compr. Physiol. 2017, 7, 1137-1150. [CrossRef] [PubMed]

134. Takeda, T.; Hoshida, S.; Nishino, M.; Tanouchi, J.; Otsu, K.; Hori, M. Relationship between effects of statins, aspirin and angiotensin II modulators on high-sensitive C-reactive protein levels. Atherosclerosis 2003, 169, 155-158. [CrossRef]

135. Anan, F.; Takahashi, N.; Nakagawa, M.; Ooie, T.; Saikawa, T.; Yoshimatsu, H. High-sensitivity C-reactive protein is associated with insulin resistance and cardiovascular autonomic dysfunction in type 2 diabetic patients. Metabolism 2005, 54, 552-558. [CrossRef] [PubMed]

136. Dwaib, H.S.; Taher, M.F.; Mougharbil, N.; Obeid, O.F.; El-Yazbi, A.F. Therapeutic fasting mitigates metabolic and cardiovascular dysfunction in a prediabetic rat model: Possible role of adipose inflammation. Faseb J. 2020, 34. [CrossRef]

Publisher's Note: MDPI stays neutral with regard to jurisdictional claims in published maps and institutional affiliations.

(C) 2020 by the authors. Licensee MDPI, Basel, Switzerland. This article is an open access article distributed under the terms and conditions of the Creative Commons Attribution (CC BY) license (http://creativecommons.org/licenses/by/4.0/). 